\title{
Clinical Profiles of Dengue Infection during an Outbreak in Northern India
}

\author{
Anish Laul, ${ }^{1}$ Poonam Laul, ${ }^{2}$ Vamsi Merugumala, ${ }^{2}$ Ravi Pathak, ${ }^{2}$ \\ Urvashi Miglani, $^{2}$ and Pinkee Saxena ${ }^{2}$ \\ ${ }^{1}$ Maulana Azad Medical College, No. 2, Bahadur Shah Zafar Marg, New Delhi, Delhi 110002, India \\ ${ }^{2}$ Deen Dayal Upadhyay Hospital, Hari Nagar, Clock Tower, New Delhi, Delhi 110064, India \\ Correspondence should be addressed to Poonam Laul; poonam_laul@yahoo.com
}

Received 2 August 2016; Revised 25 September 2016; Accepted 8 November 2016

Academic Editor: Shyam Sundar

Copyright (c) 2016 Anish Laul et al. This is an open access article distributed under the Creative Commons Attribution License, which permits unrestricted use, distribution, and reproduction in any medium, provided the original work is properly cited.

\begin{abstract}
Introduction. Dengue fever is an arboviral disease, which is transmitted by mosquito vector and presents as varied clinical spectrum of dengue fever (DF), dengue hemorrhagic fever (DHF), dengue shock syndrome (DSS), and expanded dengue syndrome (EDS) with atypical presentations, thus posing a diagnostic dilemma. Unless we are aware of these presentations, diagnosis as well as early initiation of treatment becomes difficult. We studied the various clinical presentations of dengue infection during an outbreak of disease in 2015. Materials and Methods. A total of 115 confirmed cases of dengue infection from Department of Medicine of Deen Dayal Upadhyay Hospital, New Delhi, were enrolled in this observational study. Results. The common signs and symptoms of dengue infection were fever, headache, body ache, backache, retro-orbital pain, bleeding manifestations, and rash in $100 \%$, $87 \%, 86 \%, 58 \%, 41 \%, 21 \%$, and $21 \%$, respectively. Nonspecific or warning signs and symptoms included vomiting, weakness, abdominal pain, breathlessness, vertigo, sweating, and syncope. Other possible signs and symptoms of coinfections, comorbidities, or complications included diarrhea, sore throat, and neurological manifestations. There were seven patients with coinfections and four with comorbidities. The final diagnosis of these patients was DF (73\%), DHF (16.5\%), DSS (1.7\%), and EDS (4.3\%). Among EDS patients, the atypical presentations included encephalopathy, lateral rectus nerve palsy, acalculous cholecystitis, and myocarditis. Four patients required ICU care and there was no death in this study. Conclusion. Knowledge of atypical presentations is a must for early diagnosis and timely intervention to prevent life-threatening complications.
\end{abstract}

\section{Introduction}

Dengue is a viral disease of tropical regions. The causative agent is one of serotypes of a single stranded RNA virus called DENV $1,2,3$, and 4 [1]. It is a tropical disease, which is transmitted by the Aedes aegypti mosquito. Incubation period is 4 to 7 days (range 3-14 days) [2]. Once the symptoms start, person can remain infectious for next six to seven days. In addition to mosquito bite, dengue has been reported to be transmitted by transfusion of blood from an infected donor, injuries by infected sharps to health care workers, transplantation of organs and tissues from infected donors, and from infected pregnant mother to her fetus by vertical transmission [3-5]. This viral infection has a wide clinical spectrum ranging from asymptomatic disease to undifferentiated fever (or viral syndromes), classical dengue fever
(DF), dengue hemorrhagic fever (DHF), or dengue shock syndrome (DSS) and expanded dengue syndrome (EDS) [2]. After incubation period ends, the disease is followed by three phases: febrile, critical, and recovery phase [2]. In the recent years, dengue has crossed geographic borders and has spread to many new countries. Currently, it is endemic to southeast Asia and western pacific regions [2]. So dengue fever has become a major international public concern particularly in tropical and subtropical regions affecting urban as well as rural areas. Though several measures are taken to prevent and control it, recurrent outbreaks have been reported in India. The first outbreak of dengue fever in India was in 1812 [6].

Several major outbreaks took place after this in years 1836, 1906, 1911, 1972, 2005, 2010, and 2015. An increasing number of cases of dengue are being reported with atypical presentations as frequent epidemics are occurring. As awareness of 
TABLE 1

\begin{tabular}{|c|c|c|c|}
\hline DF/DHF & Grade & Signs and symptoms & Laboratory \\
\hline DF & $\begin{array}{l}\text { With or without haemorrhagic } \\
\text { manifestations }\end{array}$ & $\begin{array}{l}\text { Fever with two of the following: } \\
\text { (i) Headache. } \\
\text { (ii) Retro-orbital pain. } \\
\text { (iii) Myalgia. } \\
\text { (iv) Arthtralgia/bone pain. } \\
\text { (v) Rash. } \\
\text { (vi) Haemorrhagic manifestations. } \\
\text { (vii) No evidence of plasma leakage. }\end{array}$ & $\begin{array}{l}\text { Leucopenia (wbc } \leq 5000 \text { cells } / \mathrm{mm}^{3} \text { ). } \\
\text { (i) Thrombocytopenia (platelet count } \\
\left.<150000 \text { cells } / \mathrm{mm}^{3}\right) \text {. } \\
\text { (ii) Rising haematocrit }(5 \%-10 \%) \text {. } \\
\text { (iii) No evidence of plasma loss. }\end{array}$ \\
\hline DHF & I & $\begin{array}{c}\text { Fever and haemorrhagic } \\
\text { manifestation (positive tourniquet } \\
\text { test) and evidence of plasma } \\
\text { leakage. }\end{array}$ & $\begin{array}{c}\text { Thrombocytopenia } \\
<100000 \text { cells } / \mathrm{mm}^{3} ; \text { HCT rise } \geq 20 \% \text {. }\end{array}$ \\
\hline DHF & II & $\begin{array}{l}\text { As in Grade I plus spontaneous } \\
\text { bleeding. }\end{array}$ & $\begin{array}{c}\text { Thrombocytopenia } \\
<100000 \text { cells } / \mathrm{mm}^{3} \text {; HCT rise } \geq 20 \% \text {. }\end{array}$ \\
\hline DHF & III & $\begin{array}{c}\text { As in Grade I or II plus circulatory } \\
\text { failure (weak pulse, narrow pulse } \\
\text { pressure ( } \leq 20 \mathrm{mmHg}) \\
\text { hypotension, restlessness). }\end{array}$ & $\begin{array}{c}\text { Thrombocytopenia } \\
<100000 \text { cells } / \mathrm{mm}^{3} \text {; HCT rise } \geq 20 \% \text {. }\end{array}$ \\
\hline DHF & IV & $\begin{array}{c}\text { As in Grade III plus profound shock } \\
\text { with undetectable BP and pulse. }\end{array}$ & $\begin{array}{c}\text { Thrombocytopenia }< \\
100000 \text { cells } / \mathrm{mm}^{3} ; \text { HCT rise } \geq 20 \% .\end{array}$ \\
\hline
\end{tabular}

this disease is increasing, rare manifestations are also being reported. During an outbreak in 2015 in Northern India, the present study was conducted in tertiary care hospital in Delhi highlighting the varied clinical presentations of dengue fever.

\section{Materials and Methods}

This was an observational study conducted on the patients selected from indoor and outdoor Departments of Medicine of Deen Dayal Upadhyay Hospital in West Delhi, India, during the period from 1 June to 31 August 2015. 115 patients suffering from dengue fever during an outbreak of the disease were enrolled. All patients who were admitted with complaint of fever and were found positive for either NS1 antigen (Micro ELISA, J. Mitra) or dengue IgM antibodies (NIV Pune) were included in the present study. A detailed history was taken and careful clinical examination was performed. Besides routine biochemical and hematological investigations [hemoglobin, total leucocyte count (TLC) and differential leucocyte count (DLC), platelet count, hematocrit (HCT), liver function tests (LFT), blood urea, and serum creatinine], malarial antigen, Slide test for malarial parasite, IgM antibodies and Widal test for typhoid, and X-ray chest and ultrasonography (USG) of abdomen were also done in all patients. Other investigations were performed according to the clinical conditions of the patients. All subjects were classified according to WHO guidelines as shown in Table 1 [2].

2.1. Criteria for Classification of Dengue Infection. Patients having neurological, cardiac, gastrointestinal, musculoskeletal, renal, ocular, and other nonspecific manifestations were grouped in expanded dengue syndrome (EDS) category. Thrombocytopenia was taken as platelet count less than $1 \mathrm{lac} / \mathrm{mm}^{3}$ and leucopenia as $\mathrm{wbc} \leq 5000 \mathrm{cells} / \mathrm{mm}^{3}$.
TABLE 2

\begin{tabular}{lcc}
\hline Age groups & Frequency & $\%$ \\
\hline $18-20$ years & 23 & $20 \%$ \\
$21-30$ years & 48 & $41.7 \%$ \\
$31-40$ years & 22 & $19.1 \%$ \\
$41-50$ years & 12 & $10.4 \%$ \\
$>50$ years & 10 & $8.7 \%$ \\
Total & 115 & $100 \%$ \\
Mean \pm SD & $31.36 \pm 13.17$ & \\
Median & 30 & \\
Min-max & $13-71$ & \\
\hline
\end{tabular}

\section{Results}

192 subjects with fever and clinical suspicion of dengue were tested for NS1 antigen and dengue IgM antibody and 115 subjects $(59.8 \%)$ of confirmed dengue fever with age more than 18 years were included in the study.

\section{Age-Wise Distribution of Patients}

Age distribution of patients is as shown in Table 2. We had 64 (57\%) males and 51 (44\%) females enrolled in our study.

\section{Clinical Presentations}

As far as clinical spectrum was concerned, all patients had come with fever along with varied clinical manifestations as shown in Table 3.65 patients $(57 \%)$ had abdominal pain, out of which 26 had right upper quadrant pain with fever. Nine patients had positive Murphy's sign. All the 26 patients with 
TABLE 3

\begin{tabular}{|c|c|c|}
\hline Symptoms & Number of patients & Percentage\% \\
\hline Fever & 115 & 100 \\
\hline Headache & 100 & 87 \\
\hline Body ache & 99 & 86 \\
\hline Backache & 67 & 58 \\
\hline Retro-orbital pain & 47 & 41 \\
\hline $\begin{array}{l}\text { Bleed (any } \\
\text { hemorrhagic } \\
\text { manifestation) }\end{array}$ & 24 & 21 \\
\hline Rashes & 25 & 21 \\
\hline Vomiting & 78 & 68 \\
\hline Weakness & 79 & 68 \\
\hline Pain abdomen & 65 & 57 \\
\hline Breathlessness & 22 & 19 \\
\hline Vertigo & 16 & 14 \\
\hline Sweating & 15 & 13 \\
\hline Syncope & 14 & 12 \\
\hline Diarrhoea & 31 & 27 \\
\hline Sore throat & 29 & 25 \\
\hline $\begin{array}{l}\text { Neurological } \\
\text { manifestations }\end{array}$ & 3 & 2 \\
\hline Itching & 22 & 19 \\
\hline Others & 9 & 8 \\
\hline
\end{tabular}

pain had edematous gall bladder without gallstones. Diagnosis of acalculous cholecystitis was made and all patients responded well to supportive therapy. 29 patients (25\%) had associated hepatomegaly and six patients (5\%) had ascites associated with hepatosplenomegaly. All 65 patients (57\%) of pain abdomen had elevated AST and 49\% had elevated ALT as shown in Table 7. There was significant difference in ALT among the four groups with elevated levels indicating the severest and atypical forms of infections in form of DHF, DSS, and EDS ( $p$ value 0.039 ) as shown in Table 8. All patients with raised AST and ALT were discharged once they showed falling trend and no patient reported to have any hepatic sequelae.

One patient with jaundice and enzymes in range of $200 \mathrm{IU}$ also recovered completely within two weeks. All other causes of jaundice were ruled out in this. Only one patient in our study had blood urea of $42 \mathrm{mg} \%$ and serum creatinine $1.6 \mathrm{mg} \%$; however he also recovered with supportive treatment without any complication. There was no hepatic or renal failure reported in our study.

22 patients (19\%) had breathlessness, out of which 18 patients (16\%) had pleural effusion on chest X-ray as shown in Table 4. Two patients were known asthmatic, one had come in respiratory failure, and another had dyspnoea due to congestive heart failure.

\section{Investigations (X-Ray, Ultrasound Abdomen, Test for Coinfections)}

For more details see Table 4.

\section{Blood Investigations}

90 patients $(78 \%)$ had thrombocytopenia with platelet count less than one lac. There was significant difference in the platelet count among the four groups, with DHF and DSS having significantly low values ( $p$ value 0.003 ). 80 patients (70\%) had leucopenia with relatively decreased lymphocyte count among the four groups, the mean value being the lowest in DSS and DHF group, respectively ( $p$ value $<0.001$ ) (Tables 5 and 6).

Clinical categorisation of subjects was done as shown in Table 9. Nineteen patients were diagnosed with DHF and two with DSS. 24 patients (20\%) had hemorrhagic manifestations in form of epistaxis, hematemesis, hemoptysis, melena, subconjunctival hemorrhage, and menorrhagia. Ten patients required both blood and platelet transfusion and five required only platelet transfusion. A total of thirty units of platelets were transfused. Intravenous fluid therapy was given according to WHO guidelines.

\section{Clinical Categorisation}

Four patients (3\%) required ICU care because of DSS, myocarditis, and encephalopathy. One patient of DSS had come with acute respiratory distress in shock with saturation of $79 \%$ and needed intubation in casualty and was transferred to ICU and put on ventilator. He had pleural effusion as well as ascites and very low platelet count. He was monitored with central line, transfused 6 units of platelets, and required ICU care for five days. Total hospital stay was eight days and patient recovered well without any residual disease.

Another patient of DSS with BP of 60/40 and haematemesis required ICU care with platelet as well as blood transfusion. His hospital stay was of 6 days. Patient responded well to platelet, blood, and fluid therapy. Another patient of encephalopathy also required ICU care.

The fourth patient requiring ICU care was an eighteenyear-old girl. She had come with fever and breathlessness which on physical examination revealed congestive heart failure. Patient was hypoxemic and hypotensive. She had thrombocytopenia, EKG revealed sinus tachycardia, X-ray chest revealed bilateral pleural effusion, and echocardiography showed pericardial effusion, global hypokinesia, and reduced left ventricular systolic function with ejection fraction of $40 \%$. Clinical diagnosis of myocarditis was made. She was treated in ICU with standard decongestive therapy, positive inotropic support, and platelet infusion. Patient responded well to treatment and had ejection fraction of $56 \%$ at the time of discharge with no long term sequelae on follow-up.

Five patients (4.3\%) had expanded dengue syndrome (EDS) affecting nervous system (encephalopathy, facial, and lateral rectus nerve palsy) in three, cardiovascular system (myocarditis) in one, and gastrointestinal system in one (jaundice). The patient with encephalopathy was brought 
TABLE 4

\begin{tabular}{lccc}
\hline Finding & Positive cases & Total & Percentage $\%$ \\
\hline Pleural effusion (PE) & 18 & 115 & 15 \\
Gall bladder edema (GBE) & 26 & 115 & 22 \\
Hepatosplenomegaly (HS) & 29 & 115 & 25 \\
Hepatosplenomegaly + ascites (HS + A) & 6 & 115 & 5 \\
Malarial antigen (R-MAT) & 1 & 115 & 0.9 \\
Slide test for malaria & 2 & 115 & 1.8 \\
Widal test & 4 & 115 & 3.5 \\
\hline
\end{tabular}

TABLE 5

\begin{tabular}{lccc}
\hline WBC count & Mean \pm SD & Median & Min-max \\
\hline Total & $3749.48 \pm 2411$ & 3000.00 & $1100-18500$ \\
N & $55.58 \pm 12.54$ & 55.00 & $25-90$ \\
L & $38.83 \pm 12.58$ & 40.00 & $9-64$ \\
M & $2.78 \pm 1.89$ & 2.00 & $0-10$ \\
E & $1.95 \pm 1.89$ & 1.00 & $0-16$ \\
\hline
\end{tabular}

TABLE 6

\begin{tabular}{lccccccccc}
\hline \multirow{2}{*}{ WBC count } & \multicolumn{2}{c}{ DF } & \multicolumn{2}{c}{ DHF } & \multicolumn{2}{c}{ DSS } & \multicolumn{2}{c}{ EDS } & \multicolumn{2}{c}{$p$ value } \\
& Mean & \pm SD & Mean & \pm SD & Mean & \pm SD & Mean & \pm SD & \pm 3267.72 \\
Total & 3398.43 & \pm 1645.59 & 4404.21 & \pm 2771.25 & 10550 & \pm 11243 & 4790 & 0.541 \\
N & 53.49 & \pm 11.93 & 63.53 & \pm 11.25 & 64.5 & \pm 28.99 & 59 & \pm 11.18 & 0.011 \\
L & 41.49 & \pm 12.07 & 29.42 & \pm 9.49 & 27 & \pm 24.04 & 31.8 & \pm 6.8 & $<0.001$ \\
M & 2.75 & \pm 1.93 & 3.11 & \pm 1.91 & 3 & \pm 1.41 & 1.75 & \pm 0.96 \\
E & 1.99 & \pm 2.07 & 1.74 & \pm 1.24 & 3.5 & \pm 0.71 & 1.5 & \pm 0.58 & 0.499 \\
\hline
\end{tabular}

TABLE 7

\begin{tabular}{lccc}
\hline & Mean \pm SD & Median & Min-max \\
\hline PL count $(\mathrm{K})$ & $52.70 \pm 38.54$ & 41.00 & $10-204$ \\
HCT & $38.86 \pm 5.91$ & 39.00 & $18.10-67.30$ \\
UREA & $18.97 \pm 5.21$ & 18.00 & $10-42$ \\
Creatine & $1.16 \pm 1.69$ & 1.00 & $0.20-17$ \\
Serum bilirubin & $1.13 \pm 0.63$ & 1.10 & $0.20-6.30$ \\
AST & $69.50 \pm 51.52$ & 50.00 & $24-346$ \\
ALT & $60.10 \pm 38.55$ & 45.00 & $20-234$ \\
\hline
\end{tabular}

TABLE 8

\begin{tabular}{|c|c|c|c|c|c|c|c|c|c|}
\hline & \multicolumn{2}{|c|}{$\mathrm{DF}$} & \multicolumn{2}{|c|}{ DHF } & \multicolumn{2}{|c|}{ DSS } & \multicolumn{2}{|c|}{ EDS } & \multirow{2}{*}{$p$ value } \\
\hline & Mean & $\pm \mathrm{SD}$ & Mean & $\pm \mathrm{SD}$ & Mean & $\pm \mathrm{SD}$ & Mean & $\pm \mathrm{SD}$ & \\
\hline$\overline{\mathrm{Hb}}$ & 12.74 & \pm 9.81 & 12.36 & \pm 4.16 & 15.25 & \pm 0.35 & 12.14 & \pm 2.14 & 0.074 \\
\hline PL count $(\mathrm{K})$ & 58.24 & \pm 41.31 & 41.11 & \pm 15.68 & 27.5 & \pm 17.68 & 14.4 & \pm 3.78 & 0.003 \\
\hline HCT & 38.48 & \pm 4.39 & 39.82 & \pm 10.21 & 43.5 & \pm 9.19 & 40.06 & \pm 7.64 & 0.706 \\
\hline Urea & 18.5 & \pm 4.75 & 20.75 & \pm 6.22 & 25 & \pm 14.14 & 19.38 & \pm 4.89 & 0.696 \\
\hline Creatine & 1.24 & \pm 1.88 & 0.83 & \pm 0.23 & 0.7 & \pm 0.42 & 0.85 & \pm 0.45 & 0.142 \\
\hline Serum bilirubin & 1.18 & \pm 0.67 & 0.89 & \pm 0.23 & 0.7 & \pm 0.42 & 1.08 & \pm 0.58 & 0.042 \\
\hline ALT & 62.85 & \pm 47.07 & 89.6 & \pm 63.61 & 128 & \pm 11.31 & 92.2 & \pm 65.74 & 0.039 \\
\hline AST & 56.18 & \pm 32.61 & 71.6 & \pm 54.61 & 79 & \pm 62.23 & 80.8 & \pm 59.91 & 0.758 \\
\hline
\end{tabular}


TABLE 9

\begin{tabular}{lcc}
\hline Categorisation & Frequency & $\%$ \\
\hline DF & 84 & $73 \%$ \\
DF with Hg & 5 & $4.3 \%$ \\
DHF & 19 & $16.5 \%$ \\
DSS & 2 & $1.70 \%$ \\
EDS & 5 & $4.3 \%$ \\
Total & 115 & $100 \%$ \\
\hline
\end{tabular}

to casualty with history of fever and altered sensorium. On examination he was found to be responding only to painful stimuli with normally reacting pupils and fundus examination. His all investigations were normal except low platelet, mildly raised ALT and AST, and positive NS1 antigen. MRI brain was inconclusive. CSF was sterile on culture with lymphocytosis and normal glucose values. Diagnosis of dengue encephalopathy was made. Patient was given supportive care in ICU with strict monitoring of electrolyte and fluid balance. He started to recover after 6 days. Recovery was prolonged with slight slurring of speech which recovered fully within next two months.

One patient reported drooping of saliva and slurred speech and another acute onset of diplopia with squint. MRI was done to exclude intracranial space occupying lesion or bleed. Provisional diagnosis of facial and lateral rectus nerve palsy was made in consultation with ophthalmologist. Both patients responded well to conservative treatment and recovered without any sequelae within eight weeks.

Out of 115 patients, seven had coinfections with malaria in three (confirmed by Slide test positive for Plasmodium vivax malarial parasite and malarial antigen) and typhoid in four confirmed with Widal test as shown in Table 3. Four patients had comorbidities with diabetes and asthma (two subjects each). Diabetic patients had their blood glucose monitored regularly. There was no death or long term disability in our study patients.

\section{Discussion}

The present study highlighted the varied spectrum of dengue fever ranging from some known clinical presentations of fever, rash, headache to some atypical presentations like acalculous cholecystitis, encephalopathy, myocarditis, and facial and lateral rectus nerve palsy. The atypical manifestations of dengue fever are increasing in recent outbreaks as evidenced by various studies.

Headache and retro-orbital pain are well-known features of dengue fever. In present study we found that $87 \%$ of patients had headache as chief complaint and $41 \%$ had typical retro-orbital pain. In study by Mandal et al. [6], 62.16\% patients presented with headache. In some studies like Itoda et al. [7], 90\% of patients presented with headache. On the other hand, Awasthi et al. [8] conducted a study in north India and reported that only $9 \%$ of cases had headache as their chief symptom.
With technological advancements like ultrasonography, more and more cases of dengue fever are being reported with ascites and pleural effusion but it is to be done at right time. We have detected third space collection in form of ascites in $6 \%$ and pleural effusion in $16 \%$ of patients. In a study by Mandal et al., [6] ascites was present in $8.1 \%$ and pleural effusion in $18.9 \%$ of cases. In Bangladesh based study by Mia et al. [9], $42 \%$ had pleural effusion and $41 \%$ of patients developed ascites. In ultrasound based study by Kalayanarooj et al. [10], pleural effusion was diagnosed in $18 \%$, which corroborated with the findings of the present study.

Hemorrhagic manifestations are a well-known complication of dengue fever due to decreased platelet count and leakage from blood vessels. Thrombocytopenia may be because of spontaneous aggregation of platelets to virusinfected endothelium, bone marrow suppression, or immune mediated clearance. In our study we found that $20 \%$ of patients had hemorrhagic manifestations in the form of epistaxis, hematemesis, hemoptysis, melena, subconjunctival hemorrhage, hematomas, and menorrhagia. Hemorrhagic manifestations were present in $40 \%$ of patients in a study by Karoli et al. [11].

In the present study, $78 \%$ of patients had platelet count $<1$ lakh. Singh et al. [12] observed thrombocytopenia in $61.39 \%$ of cases. In a study by Mandal et al. [6], 37.8\% had platelet count below 50,000 per cubic $\mathrm{mm}$ and $13.51 \%$ had hemorrhagic manifestations in the form of melena and gum bleeding. In a study by Tripathi et al. [13], only $12.8 \%$ had platelet count $<70,000$ but $28 \%$ cases had hematemesis, $26 \%$ had melena, and $14.28 \%$ had epistaxis. In a Hyderabad based study by Khan et al. [14], only $5 \%$ of patients had bleeding while $40 \%$ had thrombocytopenia.

Low leucocyte count may be due to virus-induced inhibition of myeloid progenitor cells or due to destruction. We found that $70 \%$ had leucocyte count $<5000$ almost similar to a study by Itoda et al. [7] in which leucopenia was observed in $71 \%$ of cases. Ageep et al. [15] detected leucopenia in $90 \%$ of cases while Mandal et al. [6] found leucopenia in 29.73\% of cases. Elevated transaminases are found to be raised in a large percentage of our study. Dengue fever can cause hepatic injury and elevation of transaminases. $57 \%$ of patients had elevated ALT and $49 \%$ had raised AST.

$57 \%$ of patients presented with pain abdomen along with fever. $22 \%$ had acalculous cholecystitis with right upper quadrant abdominal pain, positive Murphy's sign, abnormal liver function tests, and thickened gall bladder wall without stones on ultrasonography. The exact mechanism of acalculous cholecystitis in dengue is not known. It could be due to viral invasion of gall bladder wall causing microangiopathic injury and increased vascular permeability leading to protein rich plasma leakage. This could be the cause of thickening of gall bladder wall [1]. Severity as well as progression of dengue fevers has been found to be significantly associated with thickening of gall bladder wall in some studies. The course of disease is usually self-limiting but, in a few patients, acalculous cholecystitis progresses rapidly to ischemic gangrene and perforation. Cholecystectomy is reserved for such patients who progress to peritonitis. 
We had five cases of EDS with neurological, cardiovascular, and gastrointestinal involvement. The unusual atypical manifestations, in this study, were of neurological involvement in $3(2.6 \%)$ patients. Neurological involvement in dengue may occur because of neurotropism of the virus, immunological mechanisms, cerebral anoxia, intracranial hemorrhage, hyponatremia, cerebral edema, hepatic failure, renal failure, or release of toxic products. Peter et al. [16] reported isolated facial nerve palsy in dengue fever and Shivanthan et al. [17] have also reported isolated 6th nerve palsy. Donnio et al. [18] reported dengue with a rare presentation of oculomotor nerve palsy. Sanjay et al. [19] reported a case of optic neuropathy associated with dengue fever.

One patient was categorised as EDS due to myocarditis. This patient had benign though prolonged self-limiting course. Bhasin et al. [20] also reported a case of DHF with myocarditis mimicking DSS with hypotension and pulmonary edema.

One patient reported acute respiratory distress syndrome and needed ICU care. ARDS in dengue is due to increased permeability of alveolar capillary membrane, which results in alveolar edema leading to pulmonary dysfunction [21]. Anam et al. [22] had an unusual EDS case presenting as pancreatitis and haemothorax with respiratory distress. This complication requires early recognition and prompt management for favorable outcome.

\section{Conclusion}

Dengue is a challenging disease with multisystemic, varied, atypical, and sometimes life-threatening presentations. Awareness of these rare manifestations goes a long way in early recognition, correct diagnosis, prompt intervention, and appropriate treatment. Every aspect of dengue viral infection remains a clinical challenge. A continuous seroepidemiological surveillance, timely interventions, vaccines research, and vector control measures are needed to identify the cases so that outbreaks, complications, and mortality can be minimized.

\section{Competing Interests}

The authors declare that there is no conflict of interests regarding publication of this paper.

\section{References}

[1] S. Gulati and A. Maheshwari, "Atypical manifestations of dengue," Tropical Medicine and International Health, vol. 12, no. 9, pp. 1087-1095, 2007.

[2] WHO, "Comprehensive guidelines for prevention and control of dengue and dengue hemorrhagic fever," World Health Organization, Regional Office for South-East Asia, http://apps .searo.who.int/pds_docs/B4751.pdf?ua=1.

[3] B. Pozzetto, M. Memmi, and O. Garraud, "Is transfusiontransmitted dengue fever a potential public health threat?" World Journal of Virology, vol. 4, no. 2, pp. 113-123, 2015.

[4] F. L. Tan, D. L. Loh, K. Prabhakaran, P. A. Tambyah, and H. K. Yap, "Dengue haemorrhagic fever after living donor renal transplantation," Nephrology Dialysis Transplantation, vol. 20, no. 2, pp. 447-448, 2005.

[5] S. H. Pouliot, X. Xiong, E. Harville et al., "Maternal dengue and pregnancy outcomes: a systematic review," Obstetrical and Gynecological Survey, vol. 65, no. 2, pp. 107-118, 2010.

[6] S. K. Mandal, J. Ganguly, K. Sil et al., "Clinical profiles of dengue fever in a teaching hospital of eastern India," National Journal of Medical Research, vol. 3, no. 2, pp. 173-176, 2013.

[7] I. Itoda, G. Masuda, A. Suganuma et al., "Clinical features of 62 imported cases of dengue fever in Japan," American Journal of Tropical Medicine and Hygiene, vol. 75, no. 3, pp. 470-474, 2006.

[8] S. Awasthi, V. K. Singh, S. Kumar, A. Kumar, and S. Dutta, "The changing clinical spectrum of Dengue fever in the 2009 epidemic in north India: a tertiary teaching hospital based study," Journal of Clinical and Diagnostic Research, vol. 6, no. 6, pp. 999-1002, 2012.

[9] M. W. Mia, A. M. Nurullah, A. Hossain, and M. M. Haque, "Clinical and sonographic evaluation of dengue fever in Bangladesh: a study of 100 cases," Dinajpur Medical College Journal, vol. 3, pp. 29-34, 2010.

[10] S. Kalayanarooj, D. W. Vaughn, S. Nimmannitya et al., "Early clinical and laboratory indicators of acute dengue illness," The Journal of Infectious Diseases, vol. 176, no. 2, pp. 313-321, 1997.

[11] R. Karoli, J. Fatima, Z. Siddiqi, K. I. Kazmi, and A. R. Sultania, "Clinical profile of dengue infection at a teaching hospital in North India," Journal of Infection in Developing Countries, vol. 6, no. 7, pp. 551-554, 2012.

[12] N. P. Singh, R. Jhamb, S. K. Agarwal et al., "The 2003 outbreak of dengue fever in Delhi, India," Southeast Asian Journal of Tropical Medicine and Public Health, vol. 36, no. 5, pp. 1174-1178, 2005.

[13] B. K. Tripathi, B. Gupta, R. S. K. Sinha, S. Prasad, and D. K. Sharma, "Experience in adult population in dengue outbreak in Delhi," Journal of Association of Physicians of India, vol. 46, no. 3, pp. 273-276, 1998.

[14] A. H. Khan, A. S. Hayat, N. Masood, N. M. Solangi, and T. Z. Shaikh, "Frequency and clinical presentation of dengue fever at tertiary care hospital of Hyderabad/Jamshoro," Journal of the Liaquat University of Medical and Health Sciences, vol. 9, no. 2, pp. 88-94, 2010.

[15] A. K. Ageep, A. A. Malik, and M. S. Elkarsani, "Clinical presentations and laboratory findings in suspected cases of dengue virus," Saudi Medical Journal, vol. 27, no. 11, pp. 17111713, 2006.

[16] S. Peter, N. Malhotra, P. Peter, and R. Sood, "Isolated Bell's palsy-an unusual presentation of dengue infection," Asian Pacific Journal of Tropical Medicine, vol. 6, no. 1, pp. 82-84, 2013.

[17] M. C. Shivanthan, E. C. Ratnayake, B. C. Wijesiriwardena, K. C. Somaratna, and L. K. G. K. Gamagedara, "Paralytic squint due to abducens nerve palsy: a rare consequence of dengue fever," BMC Infectious Diseases, vol. 12, article 156, 2012.

[18] A. Donnio, L. Béral, S. Olindo, A. Cabie, and H. Merle, "Dengue, a new etiology of oculomotor paralysis," Canadian Journal of Ophthalmology, vol. 45, no. 2, pp. 183-184, 2010.

[19] S. Sanjay, A. M. Wagle, and K. G. Au Eong, "Optic neuropathy associated with dengue fever," Eye, vol. 22, no. 5, pp. 722-724, 2008.

[20] A. Bhasin, R. Kumar, K. Chandra, and R. K. Singal, "Dengue fever with myocarditis," Journal, Indian Academy of Clinical Medicine, vol. 14, no. 2, pp. 187-189, 2013.

[21] L. C. S. Lum, M. K. Thong, Y. K. Cheah, and S. K. Lam, "Dengueassociated adult respiratory distress syndrome," Annals of Tropical Paediatrics, vol. 15, no. 4, pp. 335-339, 1995. 
[22] A. M. Anam, R. Rabbani, F. Shumy, and M. M. I. Polash, "Subsequent pancreatitis and haemothorax in a patient of expanded dengue syndrome," Tropical Doctor, vol. 46, no. 1, pp. 4042, 2016. 


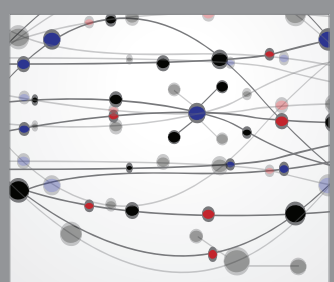

The Scientific World Journal
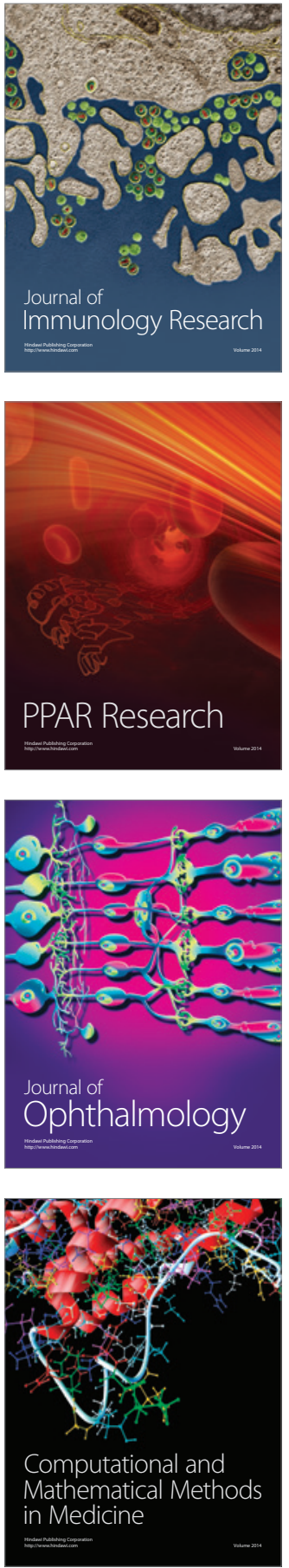

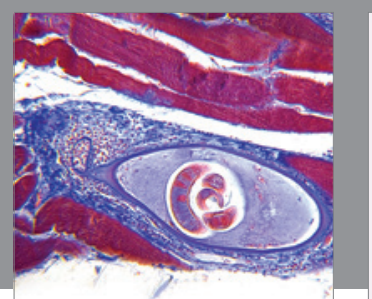

Gastroenterology Research and Practice

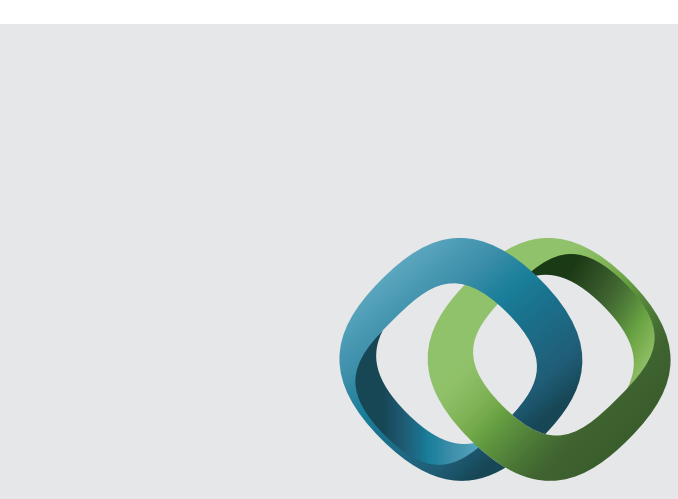

\section{Hindawi}

Submit your manuscripts at

http://www.hindawi.com
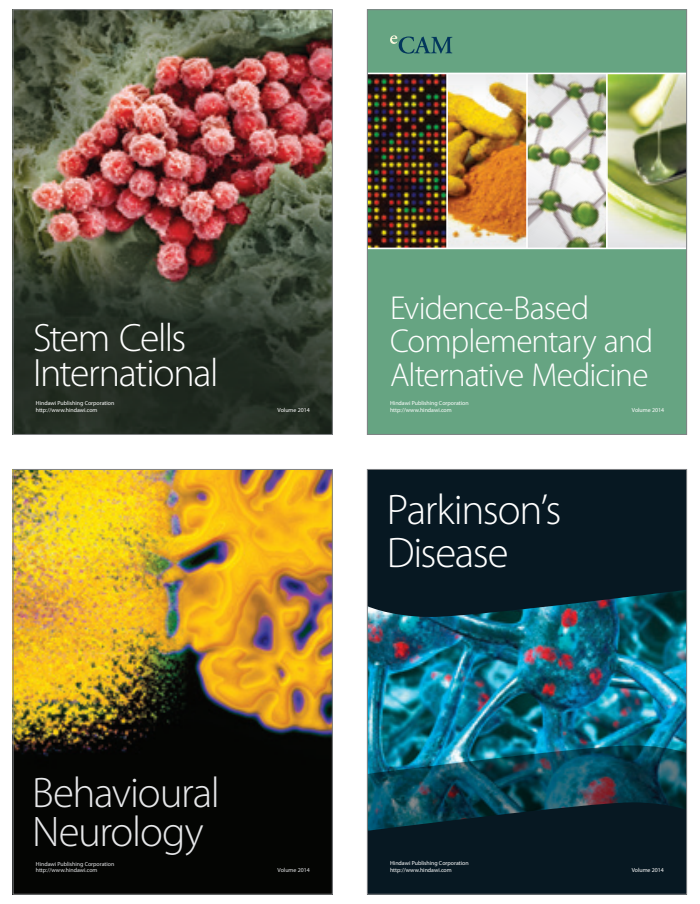
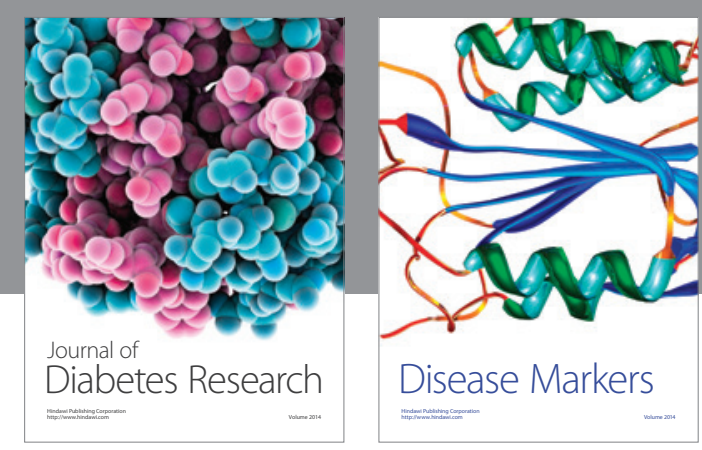

Disease Markers
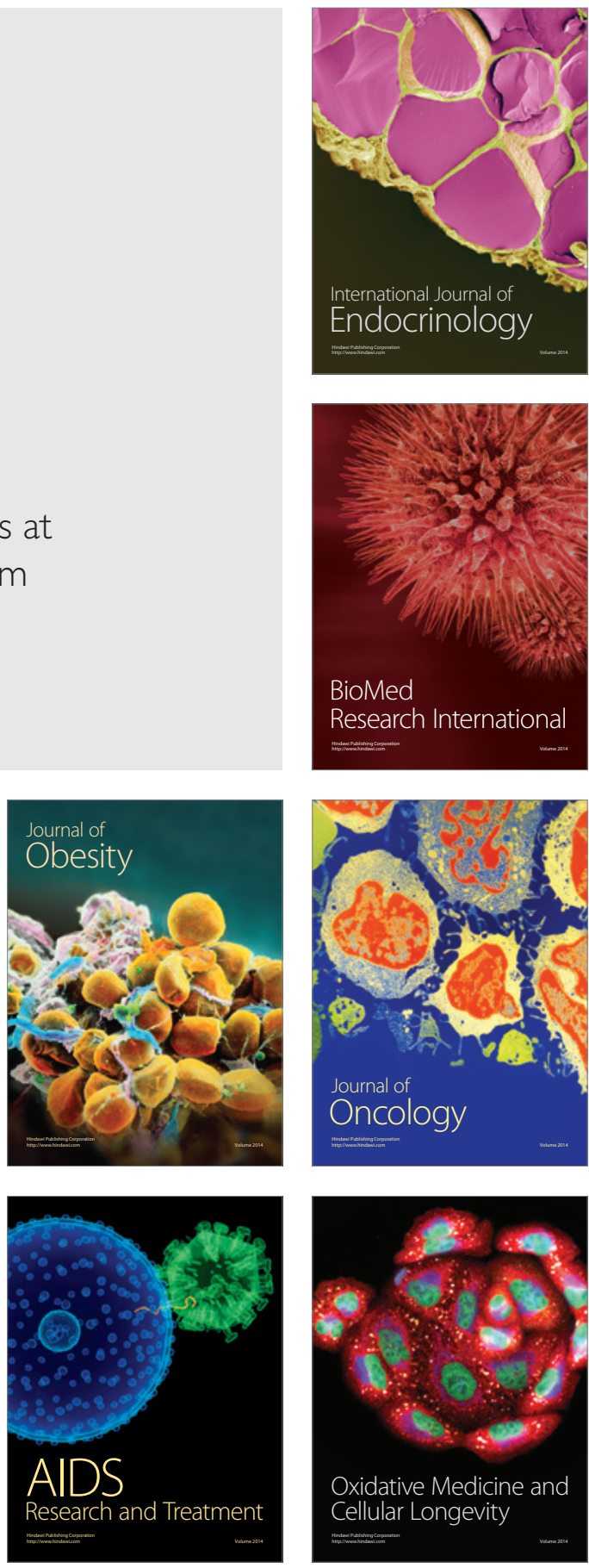